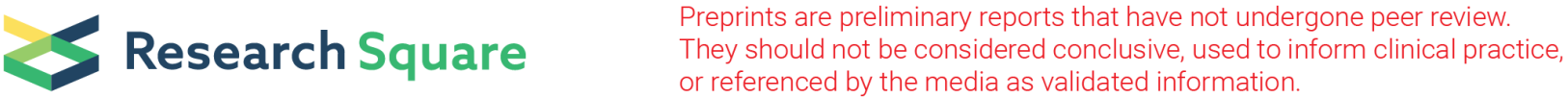 \\ [99Tc]Sestamibi Bioaccumulation Induces Apoptosis in Prostate Cancer Cells: an in Vitro Study
}

Nicoletta Urbano

Fondazione PTV Policlinico Tor Vergata

Manuel Scimeca ( $\square$ manuel.scimeca@uniroma2.it)

University of Rome Tor Vergata: Universita degli Studi di Roma Tor Vergata https://orcid.org/00000003-0585-1309

\section{Elena Bonanno}

University of Rome Tor Vergata: Universita degli Studi di Roma Tor Vergata

\section{Rita Bonfiglio}

University of Rome Tor Vergata: Universita degli Studi di Roma Tor Vergata

Alessandro Mauriello

University of Rome Tor Vergata: Universita degli Studi di Roma Tor Vergata

Orazio Schillaci

University of Rome Tor Vergata: Universita degli Studi di Roma Tor Vergata

\section{Research Article}

Keywords:

Posted Date: January 25th, 2022

DOI: https://doi.org/10.21203/rs.3.rs-1269012/v1

License: (c) (1) This work is licensed under a Creative Commons Attribution 4.0 International License. Read Full License 


\section{Abstract}

\section{Purpose}

The main aim of this in vitro study was to evaluate both the uptake of $\left[{ }^{99} \mathrm{Tc}\right]$ Sestamibi into prostate cancer cells and the relationship among $\left[{ }^{99} \mathrm{Tc}\right]$ Sestamibi bioaccumulation, cancer cells proliferation and apoptosis.

\section{Procedures}

An in vitro study in which PC3 prostate cancer cell line was cultured with increasing doses of decayed sestamibi has been developed. Specifically, PC3 cells were incubated with three different concentrations of [ ${ }^{99} \mathrm{Tc}$ ]Sestamibi: $10 \mu \mathrm{g} / \mathrm{mL}, 1 \mu \mathrm{g} / \mathrm{mL}$, and $0.1 \mu \mathrm{g} / \mathrm{mL}$ Expression of apototic markers such as caspase3 and AIF, as well as the ultrastructure of PC3 cells, were evaluated at T0 and after 24, 48, 72, and 120 hours after $\left[{ }^{99} \mathrm{Tc}\right]$ Sestamibi incubation.

\section{Results}

Data here reported for the first time showed the bioaccumulation of sestamibi in prostate cancer cells.

As concern the cancer cell homeostasis, the treatment of PC3 cells with $\left[{ }^{99} \mathrm{Tc}\right]$ Sestamibi strongly influenced the cells proliferation. Indeed, a significant reduction in the mitosis was observed.

Noteworthy, the accumulation of sestamibi in prostate cancer cells was associated with the appearance of morphological signs of apoptosis. The immunocytochemical analysis of apoptotic biomarkers, AlF and caspase 3 , in prostate cancer cells treated with $10 \mu \mathrm{g} / \mathrm{mL}$ of $\left[{ }^{99} \mathrm{Tc}\right]$ Sestamibi for confirmed that this radiopharmaceutical can induce the canonical apoptosis.

\section{Discussion}

To the best of our knowledge, this study for the first time reported in vitro data about the uptake of sestamibi in prostate cancer cells. The evidence about the accumulation of sestamibi in prostate cancer cells and its role in the apoptosis process can open new clinical perspectives on the use of this radiopharmaceutical in both the diagnosis and treatment of prostate cancers.

\section{Introduction}

Prostate cancer is one of the most frequent neoplasia that affects men in worldwide. In fact, the 2020 WHO data reported an incidence of prostate cancer of $14.1 \%$ in the male population with a prevalence of $20 \%$ [1]. In addition, prostate cancer represents the more frequent male neoplasia considering the $>60 y e a r s$ male population [1]. The onset of prostate cancer metastatic lesions often occurs several years after the first diagnosis. Thus, the development of new and ever more reliable diagnostic analysis 
capable to both predict the prostate cancer prognosis and early detect the occurrence of metastatic lesions is a great aim of the translational research.

Currently, the prognosis of prostate cancers is mainly based on the morphological evaluation of prostate biopsies and/or surgical samples [2]. Indeed, at the state of art only few molecular prognostic biomarkers have been identified for the prostate cancer [2]. Similarly, no/rare biological targets are available for precision therapy. In the last years, several researchers focused their attention of the evaluation of PSMA inhibitors as possible drugs capable to eradicate prostate cancer lesions also blocking cancer progression [3-5]. Some of these PSMA inhibitors are also radiolabeled and used to perform in vivo evaluation of prostate cancers in nuclear medicine departments [3-5]. The advantage of using radiolabeled molecules is the possibility to manage the patients during the post-diagnosis period without the need for biopsy sampling [6-8] and even to develop theragnostic approaches in which the same molecules can be used for both diagnosis and therapy by changing its concentrations or the linked radionuclide [9]. However, many of these molecules are in clinical trials still.

Hence, the identification of radiolabeled molecules showing a significant uptake in prostate cancer lesions could improve the currently armamentarium available to clinicians for managing prostate cancer patients.

A possible investigation strategy is to evaluate the specificity and sensibility for prostate cancer lesions of radiolabeled molecules already used for diagnosis or therapy of other cancers such as breast neoplasia. This strategical approach is based on the knowledge of the molecular mechanisms that drive specific radiolabeled molecules into cancer cells.

In this context, $\left[{ }^{99} \mathrm{Tc}\right]$ Sestamibi, a radiolabeled molecule used for detecting breast cancer lesions by molecular scintigraphy, could in vivo mark also prostate cancer lesions. It is known that sestamibi uptake mainly occurs for passive diffusion through biological membranes with possible accumulation into the mitochondria since the positive charge of the lipophilic structure of sestamibi $[10,11]$. In our recent study, we demonstrated that sestamibi uptake is greater in breast cancer lesions with high propensity to form bone metastasis due to the presence of osteoblast-like cells rich in mitochondria [12, 13]. Similarly, we also demonstrated that the development of bone metastasis from prostate cancer is related to the presence of prostate cancer lesions characterized by the presence of osteoblast like cells [14-16]. Thus, it is possible to hypothesize a similar uptake of $\left[{ }^{99} \mathrm{Tc}\right]$ Sestamibi in prostatic lesions. In addition, recent evidences suggest that sestamibi bioaccumulation can induce the apoptosis of cancer cells by altering the mitochondrial structure thus allowing to speculate about its use as theragnostic agent [17]. In fact, the capability of sestamibi to trigger the apoptotic process seem to be related to the concentration of drug accumulated in the cells [17].

Starting from all these considerations, the main aim of this in vitro study was to evaluate both the uptake of $\left[{ }^{99} \mathrm{Tc}\right]$ Sestamibi into prostate cancer cells (PC3) and the relationship among $\left[{ }^{99} \mathrm{Tc}\right]$ Sestamibi bioaccumulation, cancer cells proliferation and apoptosis. To this end, an in vitro study in which PC3 
prostate cancer cell line and BT-474 breast cancer cells (surrogate control) were cultured with increasing doses of decayed sestamibi has been developed. At the end of experimental phases, ultrastructural, microanalytical and immunocytochemical analysis were performed in order to evaluate the effects of sestamibi bioaccumulation on prostate cancer cells proliferation and apoptosis.

\section{Materials And Methods}

All methodologies and experimental procedures here described were achieved in agreement with the last Helsinki Declaration.

\subsection{Cell Culture}

PC3 and BT-474 cells was obtained from the American Type Culture Collection (ATCC. Manassas, Virginia, USA) and maintained by the Cell and Tissue Culture Core, Lombardi Cancer Center (Reservoir Rd. NW Washington D.C. 20057, USA). Cells were routinely cultured in DMEM high glucose (Sigma-Aldrich, St. Louis, Missouri, USA) supplemented with $10 \%$ fetal bovine serum (FBS).

In detail, cells from the first or second passage were seeded into a 24-well plate at a density of $30 \times 10^{3}$ cells/well. Then, both PC3 and BT-474 cells were incubated with: (a) $\left[{ }^{99} \mathrm{Tc}\right]$ Sestamibi $10 \mu \mathrm{g} / \mathrm{ml}$ (b) $\left[{ }^{99} \mathrm{Tc}\right]$ Sestamibi $1 \mu \mathrm{g} / \mathrm{ml}$ and (c) $\left[{ }^{99} \mathrm{Tc}\right]$ Sestamibi $0,1 \mu \mathrm{g} / \mathrm{ml}$. The expression of both $\mathrm{Ki} 67$ and caspase 3 were evaluated at T0 and after 24, 48, 72 and 120 hours after sestamibi incubation. Cells treated with the vehicle were used as control (CTRL).

Cell proliferation was investigated by counting the number of mitotic cells for each time point at the time 0 and after $72 \mathrm{~h}$. Morphology was studied both toluidine blue staining.

\subsection{Immunocytochemistry}

Immunocytochemistry was performed to investigate the expression of caspase 3 and Apoptosis-Inducing Factor (AIF) on both PC3 and BT-474 cells treated with [ $\left.{ }^{99} \mathrm{Tc}\right]$ Sestamibi. Both reactions were evaluated by immunofluorescence staining.

Cancer cells were plated on poly-I-lysine coated slides (Sigma-Aldrich cat \#P4707) in 24-well cell culture plates and fixed in $4 \%$ paraformaldehyde. After pre-treatment with EDTA citrate at $95^{\circ} \mathrm{C}$ for $20 \mathrm{~min}$ and $0.1 \%$ Triton $\mathrm{X}-100$ for $15 \mathrm{~min}$, cells were incubated $1 \mathrm{~h}$ with the anti-AIF rabbit monoclonal antibody (clone E-20, Abcam, Cambridge, UK) and anti-caspase 3 mouse monoclonal antibody (31A1067, Novus Biologicals, USA). Washings were performed with PBS/Tween20 pH 7.6. Reactions were revealed by using an TexasRed conjugate anti-rabbit antibody for AIF and an TexasRed conjugate anti-rabbit antibody for the caspase 3 .

Reactions were evaluated by counting the number of AIF or caspase 3 positive cells on 100 in total in randomly selected regions. 


\subsection{TEM and EDX Analysis of Cell Cultures}

Cells were fixed in $4 \%$ paraformaldehyde, post-fixed in $2 \%$ osmium tetroxide and embedded in Epon resin for morphological studies. After washing with $0.1 \mathrm{M}$ phosphate buffer, the sample was dehydrated by a series of incubations in $30 \%, 50 \%$, and $70 \%$, ethanol. Dehydration was continued by incubation steps in 95\% ethanol, absolute ethanol, and hydroxypropyl methacrylate, then samples were embedded in Epon (Agar Scientific, Stansted Essex, UK).

Eighty $\mu \mathrm{m}$ ultra-thin sections were mounted on copper grids and observed with Morgagni FEI 268D transmission electron microscope (FEI Company) to study the mitochondria ultrastructure.

Unstained ultra-thin sections of approximately 100-nm-thick were mounted on copper grids for microanalysis. EDX spectra were acquired by using an EDX detector (Thermo Scientific, Waltham, MA, USA) $[18,19]$.

\subsection{Statistical Analysis}

Statistical analysis was performed using GraphPad Prism 5 Software (San Diego, CA, USA). The number of mitosis and immunohistochemical data were analyzed by the Kruskal-Wallis test $(p<0.05)$ and by Mann--Whitney test $(p<0.0005)$.

\section{Results}

\subsection{Effect of sestamibi accumulation on cancer cells proliferation}

As concern the cell proliferation, a significant decrease in the number of mitosis was observed in cell cultures incubated with both $10 \mu \mathrm{g} / \mathrm{ml}$ and $1 \mu \mathrm{g} / \mathrm{ml}$ of $\left[{ }^{99} \mathrm{Tc}\right]$ Sestamibi if compared with cell treated with a concentration of $0.1 \mu \mathrm{g} / \mathrm{ml}$ (Fig. 1A-C). Indeed, data here reported showed that low concentration of $\left[{ }^{99} \mathrm{Tc}\right]$ Sestamibi $(0.1 \mu \mathrm{g} / \mathrm{ml})$ does not influence the cell proliferation (Fig. 1A-C). Cell cultures treated with $0.1 \mu \mathrm{g} / \mathrm{ml}\left[{ }^{99} \mathrm{Tc}\right]$ Sestamibi displayed a level of cell proliferation like that observed in the controls (Fig. 1A). This datum can explain the association observed in vivo between the sestamibi uptake and the percentage of mitotic cancer cells. It is important to note that high concentration of $99 \mathrm{mTC}$-sestamibi $(10 \mu \mathrm{g} / \mathrm{ml})$ induced a significant reduction of the proliferation index already after $24 \mathrm{~h}$ of treatment (Fig. 1A).

\subsection{Effect of sestamibi accumulation on cancer cells apoptosis}

One-way ANOVA showed significant data distribution for both the number of caspase $3(p=0.0131)$ and AIF $(p=0.0020)$ positive cells in the experimental groups (different time points) (Fig. 1D-I). Noteworthy, high concentration of $\left[{ }^{99} \mathrm{Tc}\right]$ Sestamibi $(10 \mu \mathrm{g} / \mathrm{ml})$ induced a significant increase in the number of 
apoptotic cells (caspase 3 or AIF positive cells) if compared with all others experimental conditions, included the controls (Fig. 1D,G). Specifically, a great increase in the number of caspase 3 positive cells was observed after 48h (Fig. 1AD). This datum suggests that only at high concentration the sestamibi could be able to induce the apoptotic process by regulation the caspase 3 signal.

\subsection{Proliferation vs apoptosis}

To investigate the effect of sestamibi on prostate cancer cell proliferation and apoptosis a comparison between caspase 3 expression data and the number of mitotic cells was performed (Fig. 2).

Specifically, it was clear that only using the $10 \mu \mathrm{g} / \mathrm{ml}$ of $\left[{ }^{99} \mathrm{Tc}\right]$ Sestamibi concentration a complete reversion between proliferation (number of mitosis) and apoptosis (caspase 3 expression) was obtained (Fig. 2A-C). In particular, after $72 \mathrm{~h}$ the number of caspase 3 positive cells were higher than those mitotic cells suggesting an imbalance capable to arrest the tumour proliferation (Fig. 2C). Similar data was observed in the BT474 breast cancer cell lines (see supplementary).

\subsection{Transmission electron microscopy and microanalysis}

Transmission electron microscope analysis of PC3 cell cultures treated with $10 \mu \mathrm{g} / \mathrm{ml}$ showed no significant ultrastructural alteration after 24 hours (Fig. 3A,B). After 72 hours of treatment cells frequently displayed alteration in the mitochondrial ultrastructure (Fig. 3C,D). Moreover, these mitochondria were often characterized by the presence of Technetium (TC) (Fig. 3D). Numerous apoptotic cells were observed after 120 hours of treatment instead (Fig. 3E-F).

\section{Discussion}

Data here reported clearly demonstrated that in vitro sestamibi bioaccumulation induces apoptosis in a prostate cancer cell line. Indeed, the treatment of PC3 prostate cancer cells with increasing concentration of decayed $\left[{ }^{99} \mathrm{Tc}\right]$ Sestamibi was able to both reduce cell proliferation and trigger the apoptosis.

The identification of new molecules capable to detect prostate cancer lesions represents one of the most important topics of the scientific research. The management of prostate cancer patients requires the continuous development of clinical investigations capable to follow the patients for several years after the diagnosis and/or treat the lesions with high metastatic potential. In fact, the onset of prostate cancer metastatic lesions often occurs several years after the first diagnosis. Currently, the follow-up for prostate cancer patients includes the use of serological tests [20], such as the blood evaluation of Prostate Specific Antigen (PSA) [20], or imaging analysis by Fluorodeoxyglucose (FDG)-Positron Emission Tomography (PET) [21] or 18 F-choline PET/Computer Tomography [22]. The PSA blood evaluation is a non-invasive test, but its values are influenced by numerous variables such as systemic inflammation and prostatitis [23]. On the contrary, molecular imaging analysis is very sensitive but more invasive respect to blood tests. 
Thus, the identification of less invasive diagnostic methods with low radiation risks, if compared with $\left[{ }^{18} \mathrm{~F}\right]$, could improve the current armamentarium available to physicians in the fight against the prostate cancer.

In this context, the low radiation exposure related to Single Photon Emission Computed Tomography (SPECT) investigations [24] might allow to design a follow-up protocol in which gamma-emitted radiolabeled molecules can be used to early detect primary or metastatic lesions. In addition, the same molecules could be used for theragnostic protocols by changing their concentration and/or the related radionuclide [25].

According to this, several gamma-emitted molecules have been tested as possible radiotracer for SPECT investigations [26]. Our recent investigations highlighted the fundamental role of 99Tc-sestamibi, in the detection of breast cancer lesions with high propensity to form bone metastasis [12,13]. Moreover, in an in vitro study the bioaccumulation of $\left[{ }^{99} \mathrm{Tc}\right]$ sestamibi was able to induce the cancer cell apoptosis in a breast cancer cell line [17].

Starting from all these evidences, and even considering the similarity of breast and prostate cancer in terms of morphology, origin and progression, especially for the development of bone metastasis, the main aim of this in vitro study was to evaluate both the uptake of $\left[{ }^{99} \mathrm{Tc}\right]$ Sestamibi into PC3 prostate cancer cells and the relationship among $\left[{ }^{99} \mathrm{Tc}\right]$ Sestamibi bioaccumulation, cancer cells proliferation and apoptosis. To this end, an in vitro study in which PC3 prostate cancer cell line and BT-474 breast cancer cells (CTRL) were cultured with increasing doses of decayed sestamibi has been developed.

Noteworthy, data here reported demonstrated the bioaccumulation of sestamibi in prostate cancer cells. Specifically, transmission electron microscopy and EDX microanalysis investigations showed the presence of technetium in both the cytoplasm and mitochondria of cancer cells.

As concern the cancer cell homeostasis, the treatment of PC3 cells with $\left[{ }^{99} \mathrm{Tc}\right]$ Sestamibi strongly influenced the cells proliferation. Indeed, a significant reduction in the mitosis was observed. Remarkable, the decrease of cell proliferation was inversely proportional to the concentration of $\left[{ }^{99} \mathrm{Tc}\right]$ Sestamibi.

In line with these data, the accumulation of sestamibi in prostate cancer cells was associated with the appearance of morphological signs of apoptosis. The immunocytochemical analysis of AIF, a mitochondrial oxidoreductase capable to trigger the cell death process [27], and caspase 3 , a caspase protein that interacts with caspase-8 and caspase- 9 sustaining the canonical intrinsic mitochondrial death pathway [28], confirmed that the treatment with [ $\left.{ }^{99} \mathrm{Tc}\right]$ Sestamibi can induce the canonical apoptosis.

The concomitant increase in the expression of caspase 3 and AIF suggests the mechanism in which $\left[{ }^{99} \mathrm{Tc}\right]$ Sestamibi may induce the apoptosis. In fact, it has been demonstrated that the caspase 3 can induce the permeabilization of the outer mitochondrial membrane, thereby triggering the release of AIF 
[29]. Hence, the $\left[{ }^{99} \mathrm{Tc}\right]$ Sestamibi bioaccumulation can induce an increase of caspase 3 expression related to a severe mitochondrial damage which in turn is responsible for the release of AIF. This hypothesis is supported by the mitochondrial alteration observed during the ultrastructure investigation in cancer cells treated with high concentration of $\left[{ }^{99} \mathrm{Tc}\right]$ Sestamibi. Similar data were obtained in the breast cancer cells lines during this study that in our previously investigations.

\section{Conclusion}

To the best of our knowledge, this study for the first time reported in vitro data about the uptake of sestamibi in prostate cancer cells. The evidence about the accumulation of sestamibi in prostate cancer cells and its role in the apoptosis process can open new clinical perspectives on the use of this radiopharmaceutical in both the diagnosis and treatment of prostate cancers. If confirmed by further ex vivo and in vitro studies, the capability of sestamibi to induce apoptosis of prostate cancer cells can lay the scientific rationale for considering this molecule as a theragnostic agent. Lastly, these investigations further highlight the fundamental cooperation between nuclear medicine, pathology and cellular biology in both research and clinical studies [30-32].

\section{Declarations}

\section{Acknowledgments}

Authors wish to thank Maria Paola Scioli and Giorgia Solidani for their technical support.

\section{Data availability}

All data were included in the manuscript.

\section{Author Contributions}

Conceptualization: N.U., M.S., and O.S.; methodology: M.S., R.B., E.B.and A.M.; formal analysis R.B., and E.B.; data curation: A.M., N.U. and O.S.; writing-original draft preparation: N.U., M.S., and O.S.; writingreview and editing: R.B., E.B. and A.M.; supervision, O.S. All authors have read and agreed to the published version of the manuscript.

\section{Conflict of Interest Statement}

Authors declare no conflict of interest

\section{References}

1. Sung H, Ferlay J, Siegel RL, et al. (2021) Global Cancer Statistics 2020: GLOBOCAN Estimates of Incidence and Mortality Worldwide for 36 Cancers in 185 Countries. CA Cancer J Clin. 71(3):209-249. 
2. Epstein Jl, Egevad L, Amin MB, et al. (2016) The 2014 International Society of Urological Pathology (ISUP) Consensus Conference on Gleason Grading of Prostatic Carcinoma: Definition of Grading Patterns and Proposal for a New Grading System. Am J Surg Pathol. 40(2):244-52.

3. Maisto C, Morisco A, de Marino R, et al. (2021) On site production of [18F]PSMA-1007 using different [18F]fluoride activities: practical, technical and economical impact. EJNMMI Radiopharm Chem. 13;6(1):36.

4. El Fakiri M, Geis NM, Ayada N, Eder M, Eder AC (2021) PSMA-Targeting Radiopharmaceuticals for Prostate Cancer Therapy: Recent Developments and Future Perspectives. Cancers (Basel). 13(16):3967.

5. Filippi L, Frantellizzi V, Chiaravalloti A, et al. (2021) Prognostic and Theranostic Applications of Positron Emission Tomography for a Personalized Approach to Metastatic Castration-Resistant Prostate Cancer. Int J Mol Sci. 16;22(6):3036.

6. Filippi L, Schillaci O (2021) Digital PET and detection of recurrent prostate cancer: what have we gained, and what is still missing? Expert Rev Med Devices. 13:1-4.

7. Zattoni F, Artioli P, Burei M, et al. (2021) Detection rate of 18F-Choline positron emission tomography/computed tomography in patients with non-metastatic hormone sensitive and castrate resistant prostate cancer. Q J Nucl Med Mol Imaging. Sep 3 doi: 10.23736/S1824-4785.21.03366-5.

8. Castellucci P, Nanni C, Ambrosini V (2018) Nuclear Medicine Imaging of Prostate Cancer in the Elderly. Semin Nucl Med. 48(6):541-547.

9. Jeong SH, Kwak C (2021) Prostate-specific membrane antigen-mediated theragnostics in prostate cancer. Investig Clin Urol. 62(5):497-499.

10. Urbano N, Scimeca M, Tancredi V, Bonanno E, Schillaci O (2020) 99mTC-sestamibi breast imaging: Current status, new ideas and future perspectives. Semin Cancer Biol. 23:S1044-579X(20)30008-0.

11. Urbano N, Scimeca M, Di Russo C, et al. (2020) [99mTc]Sestamibi SPECT Can Predict Proliferation Index, Angiogenesis, and Vascular Invasion in Parathyroid Patients: A Retrospective Study. J Clin Med. 9(7):2213.

12. Urbano N, Scimeca M, Bonanno E, Schillaci O (2019) 99mTc sestamibi SPECT: a possible tool for early detection of breast cancer lesions with high bone metastatic potential. Future Oncol. 15(5):455457.

13. Scimeca M, Urbano N, Bonfiglio R, Schillaci O, Bonanno E (2018) Breast osteoblast-like cells: a new biomarker for the management of breast cancer. $\mathrm{Br} J$ Cancer. 119(9):1129-1132.

14. Urbano N, Scimeca M, Crocco A, et al. (2019) 18F-Choline PET/CT Identifies High-Grade Prostate Cancer Lesions Expressing Bone Biomarkers. J Clin Med. 11;8(10):1657.

15. Scimeca M, Bonfiglio R, Varone F, et al. (2018) Calcifications in prostate cancer: An active phenomenon mediated by epithelial cells with osteoblast-phenotype. Microsc Res Tech. 81(7):745748.

16. Scimeca M, Urbano N, Bonfiglio R, et al. (2018) Prostate Osteoblast-Like Cells: A Reliable Prognostic Marker of Bone Metastasis in Prostate Cancer Patients. Contrast Media Mol Imaging. 2018:9840962. 
17. Urbano N, Scimeca M, Bonfiglio R, et al. (2021) [99mTc]Tc-Sestamibi Bioaccumulation Can Induce Apoptosis in Breast Cancer Cells: Molecular and Clinical Perspectives. Applied Sciences. 11(6):2733.

18. Bischetti S, Scimeca M, Bonanno E, et al. (2017) Carotid plaque instability is not related to quantity but to elemental composition of calcification. Nutr Metab Cardiovasc Dis. 27(9):768-774

19. Bonfiglio R, Scimeca M, Toschi N, et al. (2018) Radiological, Histological and Chemical Analysis of Breast Microcalcifications: Diagnostic Value and Biological Significance. J Mammary Gland Biol Neoplasia. 23(1-2):89-99.

20. Heidenreich A, Bastian PJ, Bellmunt J, et al. (2014) EAU guidelines on prostate cancer. Part II: Treatment of advanced, relapsing, and castration-resistant prostate cancer. Eur Urol. 65(2):467-79.

21. Jadvar H (2016) Is There Use for FDG-PET in Prostate Cancer? Semin Nucl Med. 46(6):502-506.

22. Castellucci P, Ceci F, Fanti S (2018) Imaging of Prostate Cancer Using 11C-Choline PET/Computed Tomography. Urol Clin North Am. 45(3):481-487.

23. Mishra SC (2020) A discussion on controversies and ethical dilemmas in prostate cancer screening. J Med Ethics. 6:medethics-2019-105979.

24. Brix G, Nekolla EA, Borowski M, Noßke D (2014) Radiation risk and protection of patients in clinical SPECT/CT. Eur J Nucl Med Mol Imaging. 41 Suppl 1:S125-36.

25. Filippi L, Chiaravalloti A, Schillaci O, Cianni R, Bagni O (2020) Theranostic approaches in nuclear medicine: current status and future prospects. Expert Rev Med Devices. 17(4):331-343.

26. Bybel B, Brunken RC, DiFilippo FP, et al. (2008) SPECT/CT imaging: clinical utility of an emerging technology. Radiographics. 28(4):1097-113.

27. Candé C, Cecconi F, Dessen P, Kroemer G (2002) Apoptosis-inducing factor (AIF): key to the conserved caspase-independent pathways of cell death? J Cell Sci. 15;115(Pt 24):4727-34.

28. Choudhary GS, Al-Harbi S, Almasan A (2015) Caspase-3 activation is a critical determinant of genotoxic stress-induced apoptosis. Methods Mol Biol. 1219:1-9.

29. Candé C, Vahsen N, Garrido C, Kroemer G (2004) Apoptosis-inducing factor (AIF): caspaseindependent after all. Cell Death Differ. 11(6):591-5.

30. Scimeca M, Urbano N, Bonfiglio R, et al. (2020) Imaging Diagnostics and Pathology in SARS-CoV-2Related Diseases. Int J Mol Sci. 22;21(18):6960.

31. Schillaci O, Scimeca M, Toschi N, et al. (2019) Combining Diagnostic Imaging and Pathology for Improving Diagnosis and Prognosis of Cancer. Contrast Media Mol Imaging. 1;2019:9429761.

32. Urbano N, Scimeca M, Bonanno E, Schillaci O (2018) Nuclear medicine and anatomic pathology in personalized medicine: a challenging alliance. Per Med. 15(6):457-459.

\section{Figures}



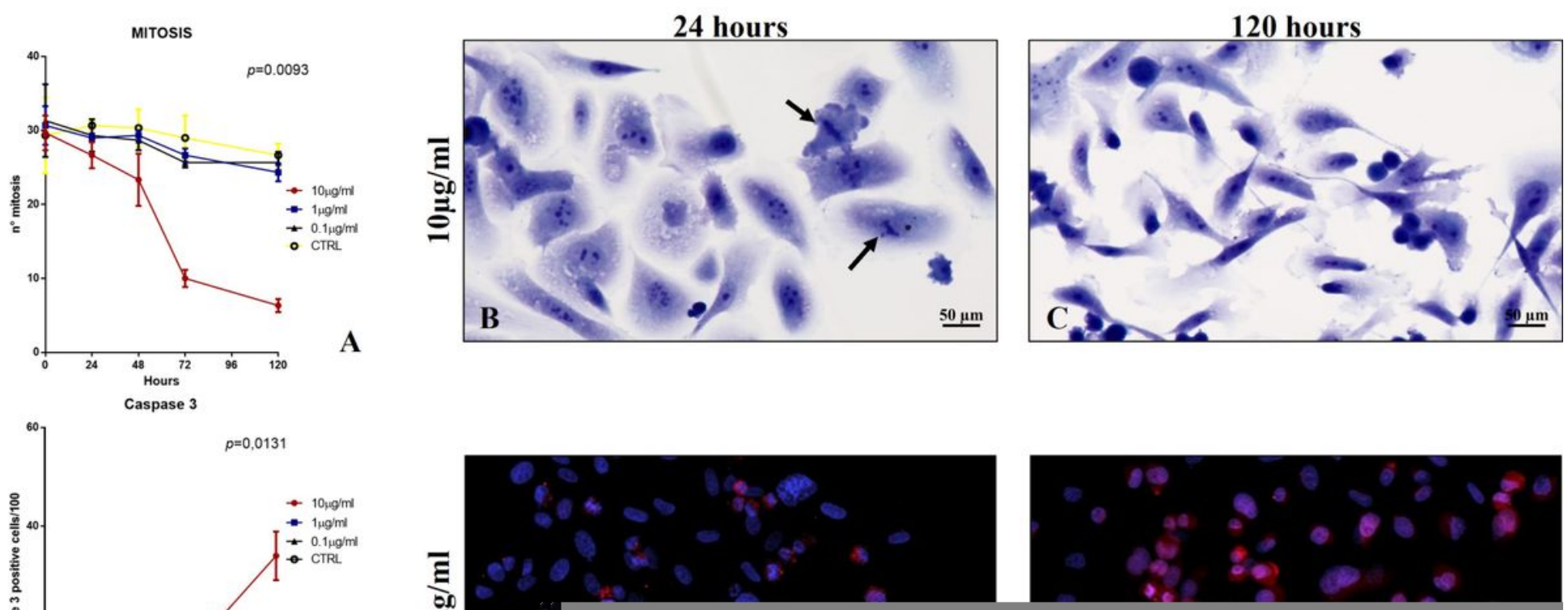

\section{Figure 1}

Evaluation of Mitosis and apoptotic phenomenon in PC3 cell lines. A) The graph shows the number of mitosis in PC3 cancer cells after sestamibi treatment. B) Image displays two mitoses (arrows) in PC3 cells treated for 24 hours with sestamibi. C) After 120 hours of sestamibi treatment no/rare mitosis are observed. D) The graph shows the number of caspase 3 positive cells after sestamibi treatment. E) Few caspase 3 positive PC3 cells after 24 hours of sestamibi treatment. F) Numerous caspase 3 positive PC3 cancer cells after 120 hours of sestamibi treatment. G) The graph shows the number of AlF positive cells after sestamibi treatment. $\mathrm{H}$ ) After 24 hours of the treatment with sestamibi no/rare AIF positive cells are detected. I) Several caspase 3 positive PC3 cancer cells after 120 hours of sestamibi treatment. Scala bar represents $100 \mu \mathrm{m}$. 

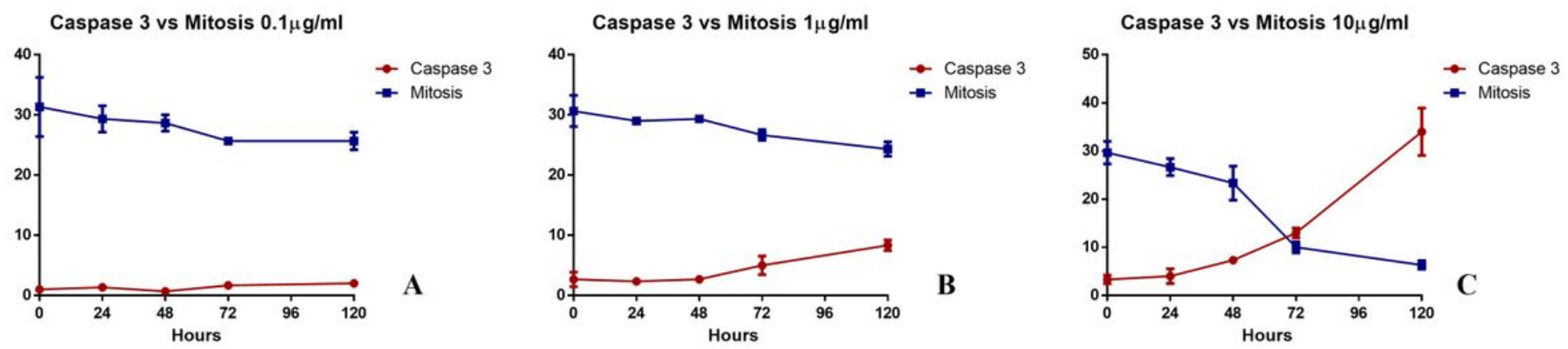

Figure 2

Comparison between caspase 3 expression and mitosis in PC3 cancer cells treated with [ $\left.{ }^{99} \mathrm{Tc}\right] \mathrm{Sestamibi}$. A) Graph shows the number of both caspase-3 positive cells and mitosis in PC3 cells after 24, 48, 72, 96, and $120 \mathrm{~h}$ of [99Tc]Sestamibi incubation $(10 \mu \mathrm{g} / \mathrm{mL})$. (B) Graph displays the number of both caspase-3 positive cells and mitosis in PC3 cells after $24,48,72,96$, and $120 \mathrm{~h}$ of [99Tc]Sestamibi incubation (10 $\mu \mathrm{g} / \mathrm{mL}$ ). (C) Graph shows the number of both caspase-3 positive cells and mitosis in PC3 cells after 24, $48,72,96$, and $120 \mathrm{~h}$ of [99Tc]Sestamibi incubation $(10 \mu \mathrm{g} / \mathrm{mL})$.

\section{Figure 3}

Transmission electron microscopy and microanalysis. A) PC3 Prostate cancer cells rich in mitochondria after 48 hours of sestamibi treatment. Scale bar represents $20 \mu \mathrm{m} \mathrm{B)} \mathrm{High} \mathrm{magnification} \mathrm{of} \mathrm{panel} \mathrm{A}$ displays no mitochondrial alterations. Scale bar represents $2 \mu \mathrm{m} \mathrm{C)} \mathrm{PC3} \mathrm{Prostate} \mathrm{cancer} \mathrm{cells} \mathrm{rich} \mathrm{after} 72$ hours of sestamibi treatment. Scale bar represents $20 \mu \mathrm{m}$ D) High magnification of panel C displays moderate mitochondrial alterations. EDX spectrum demonstrated the presence of Technetium (Tc) into the degenerated mitochondria. Scale bar represents $2 \mu \mathrm{m}$ E,F) Several apoptotic PC cancer cells after 120 hours of sestamibi treatment. Scale bar represents $20 \mu \mathrm{m}$.

\section{Supplementary Files}

This is a list of supplementary files associated with this preprint. Click to download.

- Supplementary.jpg 